\title{
Review of Expectations around Public Safety in the Covid-19 Era
}

\author{
Maria Del RMG, Cruz GL*, Sofia LNT and Alejandra NQ \\ Autonomous University of Mexico State, UAEMEX, Mexico
}

*Corresponding author: Cruz Garcia Lirios, Autonomous University of Mexico State, Department Social Work, UAEMEX, Mexico, Tel: (52) 5539026153; Email: cggarciali@uaemex. $\mathrm{mx}$

\section{Review Article \\ Volume 5 Issue 2}

Received Date: November 01, 2021

Published Date: December 03, 2021

DOI: $10.23880 /$ phoa-16000192

\section{Abstract}

The objective of this work was to contrast a model for the study of organizational security. A cross-sectional, correlational and confirmatory study was carried out with a non-probabilistic selection of 100 micro entrepreneurs from central Mexico. A three-dimensional factorial structure was found that explained $76 \%$ of the total variance, suggesting the extension of the study to other scenarios and samples, as well as the inclusion of other variables that the literature identifies as confidence in technology and leadership.

Keywords: Globalization; Locality; Model; Intangibles; Intellectual Capital

\section{Introduction}

Organizational security has been proposed as a construct to account for the importance of crime prevention in companies whose value lies in the creation of knowledge [1]. In this way, public safety from the psychology of crime is the result of the sum of intentions and actions aimed at the commission of a crime that damages or injuries the interests of third parties in terms of their heritage, stability or integrity, but such approach ignores the context of legitimation of violence that opens the discussion about the nature of crime as inherent to human genetics or as a result of the deprivation of resources for personal, group or social development.

However, the sociological perspective of violence doesn't clarify whether once the genetic version has been discarded, the opportunities would not be determining the commission of a crime, mainly that which consists of damage to the property of others, fraud or extortion to people who, due to their business function your protection and safety is in the public interest Bolivar E, et al. [2]. In this way, public security, from the integrating perspective of Social Work, lies in the balance between the demands and opportunities of the environment with respect to the capacities and resources of the political and social, public and civil actors with respect to the crime prevention and the administration of justice.

Do the theoretical frameworks related to public security in the organizational field (hereinafter organizational security) to assume that the commission of a crime can be observed and compared with other cases and consequently, anticipate its effects and reduce its impact on business dynamics explain the phenomenon in a local context where there is a high rate of assaults, kidnappings, extortion, injuries and fraud against micro-entrepreneurs?. The theories that explain the axes and trajectories of discussion around organizational security warn that it is possible to observe and predict the phenomenon in local contexts of high corruption: crimes, impunity, neglect, opacity and nepotism [3]. Although the theoretical frameworks have explained and anticipated the criminal problems associated with corruption, the specificity of local cases means that we are facing uncertain events around which it is not possible to explain or predict the risks and threats posed by a structure corruption at all levels of government, as well as the degree of collusion with local and international crime to the detriment of business dynamics. 
Public Health Open Access

\section{Governance of Corporate Public Safety}

Business public security refers to the alleged occurrence of crimes registered in previous investigations initiated, or investigation files, reported by the Attorney General's Offices and Attorney General's Offices of the 32 federal entities, who are responsible for the veracity and updating of the data (Public Security System, 2015). Linked to the notion of public security, reintegration supposes the generation of new belief systems in ex-convicts, considering that only in this way can they accept, and therefore carry out, behaviors that are socially approved by the prisoner's individuals [4].

In the organizational sphere, corporate public safety and the recruitment of human resources limited to labor reintegration make up a climate of relationships known as professional training that has its correlate in stress, mobbing or stalking in the case of digital protocols. In this way, formative violence is indicated by asymmetric and inequitable relationships between the members of the network, a management replaced by dogmas; the freedoms displaced by discretion; opportunities due to impositions, capacities reduced to their minimum expression in the face of kinship and co-responsibilities are inhibited by attributions of guilt Carreon J, et al. [5].

Consequently, the management and administration system of responsibilities between aggressors and victims within organizations is known as governance. It is a new style of government, different from the hierarchical and market control model, characterized by a greater degree of cooperation between governments and public administrations and non-governmental actors in the making of public policies. It is expected that, through this policymaking process, based on collaboration, consensus and the participation of different actors, the results and yields of the policies will be improved and, ultimately, the governance of the political system will be guaranteed.

In the governance process, civil participation oriented towards the incidence of public policies, understood as the process by which citizens, social, economic and institutional actors participate or influence the definition, management and control of general public policies or Sectorial, at local, provincial, departmental, national and institutional levels, involves creating, modifying or enforcing and/ or repealing public policies [6].

However, the security panorama is far from the theoretical explanation put forward. Indicated by levels of crime commission, prevention and administration of justice, it is possible to observe a systematic increase in the differences between the three categories in favor of complaints regarding cases processed and sentenced $[7,8]$.

\section{Theory of Public Safety}

Theoretical frameworks that explain the governance of public security warn that the differences between bureaucratic models focused on reporting and the administration of justice with respect to post-bureaucratic models focused on crime prevention through civil training pose:

- The prevalence of self-management by reducing the role of the State gendarme;

- The return of the autocratic state in the management and administration of judicial processes and

- The establishment of co-management assuming a shared responsibility among the actors Campos G, et al. [9].

The theory of justice that demonstrated the insufficiencies of intuitionism (an ideology that considered people to select what is good and what is bad) and the relevance of complementing a historical dilemma: freedom versus equality to solve the problem of freedom. Social injustice generated by the liberal State Carreon J, et al. [10].

The social structure of the welfare state promoted social justice through institutions that took social equity for granted (people are born with the same opportunities). This problem was overcome based on three foundations [11]:

- Everyone has the equal right to the broadest freedom compatible with equal freedom for all.

- Inequalities are unacceptable unless it is reasonable to expect that they will act in the best interests of all.

- Therefore, positions and trades must be open to everyone.

Freedom was the consciousness of necessity, consequently, inequality implied exclusive opportunities for a few individuals. The liberal State as immoral and unjust and proposed a theory with its corresponding method that vanished and overcame a false dichotomy: freedom versus equality. The reconciliation of both values materialized in a social contract. It was about the configuration of two forms of State (benefactor and liberal) based on a moral synthesis [12].

A theory of social justice and a method of reflective equilibrium emerged from the problematic of the immorality of the minimal liberal state. In this sense, the comprehensive values of tolerance and plurality of moral visions oriented to compatible demands. It is in this sense that the theory of social justice established the moral and legal, political and social, liberal and democratic foundations for a just liberal democratic society. Therefore, it is an interpretive and heuristic approach (it assumes criticism and adjusts its approaches) to political systems [13]. 
There are seven fundamentals around the just liberal state:

- The perception of freedom.

- The subsequent beliefs around equal opportunity.

- The consequent values of equality.

- The necessary moral individual who seeks the social good from establishing a reflective equilibrium point between the values of equality and the perceptions of freedom.

- The obvious cooperation and subsequent involvement.

- The resulting just democratic society; cooperative, orderly and stable.

- The inevitable redistribution of wealth from the liberal state for a full life.

The principle of maxim in (rational choice of a political system of lower costs versus higher benefits through a social contract) assumed that freedom and equality are principles of justice, at an institutional level; they were criteria that guided citizen decisions $[14,15]$. The principles of equality had their counterweights in the principles of differences. These social, political and economic inequalities benefited the least advantaged. Consequently, equity (open opportunities in obtaining trades) emerged.

Both principles revealed the inadmissibility of utilitarian thinking that justified the social, political and economic advantages for individuals. Framed by the concept of reflective balance between social structure and individual decisions, each citizen accepts the two principles of justice to build an ordered society with morally free and equal individuals [16].

In this way, the State was raised as a redistributor of wealth. Through its institutions, it would face the hegemonic interests that appeal to the principle of freedom to profit from public services. In this sense, the freedom of consensus as the capacity that individuals have to choose, do and be was the main instrument in the conception of the just State [17].

In this sense, the social impact of the radical liberal State in relation to the classical liberal State supposes a minimal form of State as the only permissible and justifiable for a liberal society. This minimal form of state violated individual rights. However, in the liberal conception, those of free thought and property determined the protective function of the State. The difference between individual needs hampered cooperation between people. In other words, each autonomous member is equal in their rights but not in their obligations of solidarity. Morally, the decision of each individual implied their responsibility [18].

In this sense, the welfare state by interfering in the freedoms of individuals directly, negatively and significantly affected the functioning and social structure, political and commercial rights of people. This is how a minimal State should only guarantee the right to property and the corresponding security [19]. Therefore, the liberal state was a relevant option because it promoted individual rights. However, historically the state has expropriated properties to transfer them to elite. The state has transferred properties to private individuals who have not proven they deserve said assets. Therefore, the State is immoral [20-22].

In contrast, the maximum state as illegitimate as usurper and redistributor. Both functions would belong to the rationality of individuals who can decide to quote, buy, sell, and exchange or give away their goods. The State was illegitimate because it restricted these initiatives to individuals. Therefore, poverty and social exclusion were consequences of the immorality and impertinence of the state. Furthermore, the state has been ineffective in distributing wealth. Finally, the solution to social injustice is promoting a new morality in civil society [23].

- The utopias of moral change can be framed in the minimal state: civil rights.

- However, under the liberal state it was not possible to change individualistic human morality to collectivist morality.

- In addition, it was essential to change the legal framework to activate moral change.

- Therefore, society also had to change its habits more than its values.

Decision-making knowledge and communication skills imply the construction of a leading moral entity (State, group or individual). It is in democracies governed by the representation of majority wills and proportional minorities rather than by oligarchies, dictatorships or tyrannies, where both liberal approaches are relevant. However, this liberal democratic structure was incompatible for both individual growth and community development [24]. In this sense, equal opportunity is different from equal results. The social State by promoting equity also restricts the freedom of economic growth by planning production and regulating supply and demand $[25,26]$.

\section{Studies of Public Safety Expectations}

Roughly speaking, the expectations around globalization refer to the expected consequences of strategic alliances between multinationals and SMEs around local development, but their importance lies in the exploration of organizational climates conducive to networks, management, production and transfer of resources. Innovations aimed at positioning brands in the local market and their consolidation in the international arena. 


\section{Public Health Open Access}

The expectations around globalization, for the purposes of this paper, allude to the probable consequences of alliances between multinationals and SMEs in the framework of local development. This is so because the communities and neighborhoods peripheral to the cities develop a semi-urban identity, attachment to the place and sense of belonging that limits the positioning of multinationals, but also inhibits the emergence of SMEs, resulting in the alliance between these two hegemonic actors.

However, studies related to strategic alliances between SMEs and multinationals show that both are guided by local needs, but also by innovations that allow their insertion in the local market [27]. In this way, the networks, management, production and transfer of innovations suppose intangible assets and intellectual capital that both entities must weigh in order to be able to achieve the competitive advantages that allow the positioning of their brands and the consolidation of their business models [8]. In such scenarios, consumers' perceptions of risk imply expectations of the consequences of establishing strategic alliances on the local agenda. It is a phenomenon in which peripheral communities and neighborhoods rather resist the lifestyles and consumption that alliances between multinationals and SMEs imply.

Globalization is part of a process in which localization is its antagonistic complement. This means economic and human flows concentrated in developed cities at the same time that those who remain in their places of origin take root, identifying with the global world through the mass media. Internet, as the main window to images and discourses, promotes ideas and feelings of plurality such as freedom of choice and competition. In contrast, feelings of solidarity develop in community areas. Both are consequences of the global and the local that are located in five dimensions [19].

Globalization being a reversal of closed societies that increased equality of results and decreased individual freedoms due to the absence of their rights and authoritarian regimes. It implies a new different social, economic and political system that can be built from the concatenation of its consequences. That is, regardless of equality and freedom, the consequent affectivity and rationality, the subsequent solidarity and competition, are the factors to reverse an unjust system for economically marginalized minorities [13].

The imbalance between equality and freedom can be reversed from its consequences concentrated in solidarity and competition. This suggests excluding the state bureaucracy, allowing community self-management and the development of a self-education system [28]. Local expectations in the face of globalization, indicated by the expected profits, risks, opportunities and capacities, suppose a scenario of competitive advantages based on intangible assets and intellectual capital, among which expectations stand out as factors of anticipation to conflicts or disagreements between economic, political and social actors. In the deck of expectations, the profits perceived as emerging factors in strategic alliances between multinationals and SMEs stand out, although their relevance lies in the balance posed by external demands and internal resources in organizations, their function is in the task climate, which would determine the climate of innovations and the climate of support.

However, inherent to the profits received the strategic alliances between multinationals and SMEs pose risks in the transfer of knowledge rather than in the management or production of innovations for the local market. An increase in risks not only implies a reduction in expected profits, but also implies an increase in capacities since, in the task environment where risks operate; these are corrected with empathy, trust and commitment. Consequently, the prevailing climate of relationships with respect to the climate of tasks, supports or trusts opens opportunities in management and production rather than in the transfer of information since, in knowledge networks, task climates are hegemonic. If the opportunities emerge from the climate of supports and tasks, then the capabilities will be distinguished by their degree of skills and knowledge inherent in the climate of innovations. This is that skills precede innovations, but underlie relationships of trust and empathy, if not commitment. The study of the expectations of the consequences of the globalization process focused on the strategic alliances between multinationals and SMEs involves observing the opportunities and capacities of knowledge management rather than production and transfer.

However, a scenario that is distinguished by a high degree of relationships of empathy, trust and commitment rather than by the proper functioning of its management, production and knowledge transfer structures implies more expectations of risk than expectations of benefit. Hernandez J, et al. [29]; Limon GA, et al. [30]; Sanchez A, et al. [31]; Sandoval $\mathrm{FR}$, et al. [32] $\mathrm{r}$ extol identity as the common denominator between the imbalances that promote the multinationals in SMEs, values and local norms, expectations focus on a type of identity resulting from the organizational climate rather than the context in which it is framed. However, a comparative study between localities with and without strategic alliances of multinationals with SMEs will make it possible to establish significant differences, if any, or to establish the incidence of economic and political actors on social actors, mainly in talents, intangible assets and intellectual capitals.

\section{Methodology}

- Sample: In a first exploratory, cross-sectional qualitative and quantitative study, a non-probabilistic selection 
was made of 100 micro entrepreneurs. The selection criterion was to belong to the system of practices and social service in organizations and institutions with and without profit aims of the municipality of Chimalhuacan, State of Mexico.

- Instrument: The Carreón Organizational Security Expectations Scale (2014) was used, which includes 15 statements around three dimensions related to the risks and benefits of investing in recruiter, technological and inter-personnel security. Each item is answered with one of five options ranging from $0=$ not likely, $1=$ very unlikely, 2 = unlikely, 3 = moderately likely, $4=$ very likely, 5 = quite likely.

- Process: Participants were surveyed through their emails, after telephone contact. They were informed that the results of the investigation would neither positively nor negatively affect their school situation. They were asked to answer the questions and statements honestly. They were invited to consult the results in the final report of the research group. The data were processed in the Statistical Package for Social Sciences (IBM- SPSS Amos for its acronym in English version 25.0).

- Analysis: The parameters of kurtosis, Cronbach's alpha, KMO coefficients, Bartlett's test, factorial weights, Pearson correlations, "phi" covariances, "beta" and "range" weights, as well as fit indices and residuals were used to specify the model of specified relationships with the observed data. A confirmatory factor analysis of principal components was carried out with varimax rotation, as well as the counting of the model with the adjustment and residual parameters.

\section{Analysis}

Table 1 shows the psychometric properties of the instrument that measures the three dimensions related to the risks and benefits of investing in business, technological and personal security, which exceeded the required consistency level (alpha of 0.700).

\begin{tabular}{|c|c|c|c|c|c|c|c|}
\hline & Item & M & SD & A & F1 & F2 & F3 \\
\hline & Recruiter Safety Expectations Subscale & & & $\mathbf{0 . 7 8}$ & & & \\
\hline r1 & I will issue credentials to identify employees & 3.2 & 1.01 & 0.761 & & & 0.326 \\
\hline r2 & I will research employees before hiring them & 3.24 & 1.02 & 0.751 & & & 0.346 \\
\hline r3 & I will review the letters of recommendation before hiring & 3.56 & 1.04 & 0.75 & & & 0.329 \\
\hline r4 & I will integrate the files of employees to know their profile & 3.82 & 1.05 & 0.766 & & & 0.31 \\
\hline r5 & I will visit the homes of future employees before hiring them & 3.01 & 1.02 & 0.703 & & & 0.305 \\
\hline & Expected technological security subscale & & & 0.777 & & & \\
\hline r6 & I will install video cameras in every corner of the company & 3.82 & 1.05 & 0.701 & & 0.317 & \\
\hline r7 & I will install microphones to listen to the conversations of & 3.42 & 1.08 & 0.762 & & \multirow{2}{*}{0.305} & \\
\hline r8 & I will install metal detectors at the company entrances & 3.47 & 1.02 & 0.75 & & 0.304 & \\
\hline r9 & I will install alarms connected to the police station & 3.56 & 1.09 & 0.753 & & 0.392 & \\
\hline r10 & I will install a panic room in the company offices & 3.06 & 1.02 & 0.701 & & 0.301 & \\
\hline & Subscale expectations safety inter-staff & & & 0.765 & & & \\
\hline r11 & I will hire bodyguards for my personal safety & 3.26 & 1.01 & 0.752 & 0.307 & & \\
\hline r12 & I will hire bodyguards for the safety of my partner & 3.24 & 1.03 & 0.755 & 0.306 & & \\
\hline r13 & I will hire bodyguards for my family & 3.56 & 1.05 & 0.753 & 0.391 & & \\
\hline r14 & I will hire bodyguards for my partners & 3.2 & 1.08 & 0.75 & 0.382 & & \\
\hline r15 & I'll hire bodyguards for my talents & 3.21 & 1.05 & 0.749 & 0.302 & & \\
\hline
\end{tabular}

Table 1: Instrument descriptions.

Source: Elaborated with data study; Extraction method: main axes, promax rotation. Suitability and sphericity $\int_{X^{2}}=234.35$ (12gl) $\mathrm{p}=0.000 ; \mathrm{KMO}=0.756 \mathrm{M}=\mathrm{Mean}, \mathrm{SD}=$ Standard Deviation, $\mathrm{A}=$ Crombach's Alpha removing the item value, $\mathrm{F} 1=\mathrm{Recruiter}$ Safety Expectations (34\% of the total variance explained and alpha of 0.780), F2= Safety Expectations Technological (22\% of the total explained variance and alpha of 0.777$), F 3=$ Interpersonal Safety Expectations (18\% of the total explained variance and alpha of 0.765 ). All the items are answered with one of five options: $0=$ not likely, $1=$ very unlikely, $2=$ unlikely, $3=$ moderately likely, 4 = very likely, 5 = quite likely. 
The correlations were estimated to establish the relationships between the three factors of recruitment safety expectations, technological safety expectations and interpersonal safety expectations, as well as the covariances to establish the possible relationships of the three factors with others that the literature identifies as expectations of consensual or co-responsible security (Table 2).

\begin{tabular}{|c|c|c|c|c|c|c|c|c|c|}
\hline & M & SD & $\mathbf{N}$ & F1 & F2 & F3 & F1 & F2 & F3 \\
\hline F1 & 23,12 & 14,35 & 100 & 1 & & & 1,751 & & \\
\hline $\mathrm{F} 2$ & 24,35 & 16,54 & 100 & $0.561 *$ & 1 & & 0.437 & 1,861 & \\
\hline F3 & 22,36 & 14,25 & 100 & $0.482 * *$ & $0.328 * *$ & 1 & 0.504 & 0.672 & 1,895 \\
\hline
\end{tabular}

Table 2: Correlations and covariances between factors.

Source: Elaborated with data study; M= Mean, SD= Standard Deviation, N= Sample, F1= Recruiter Safety Expectations; F2= Technological Security Expectations; F3= Personal Safety Expectations

${ }^{*} \mathrm{p}<0.1 ;{ }^{* *} \mathrm{p}<0.001 ;{ }^{* * *} \mathrm{p}<0.0001$.

It is possible to notice that there are direct, positive and significant associations between the factors that allow inferring their convergence in a structural model, as well as in the case of covariances, the inclusion of the factors that the literature identifies as collateral. The total variance explained of the construct was $74 \%$, which denotes a high percentage of explanation of the phenomenon of organizational security, which is why a model of reflective relationships between items and factors was contrasted.

It is possible to appreciate that the model presents relationships close to zero which suggest that other factors and indicators could be included. In the case of measurement errors, some are close to unity, suggesting the inclusion of other indicators in the factor.

The structural model includes the associations between the three factors and with respect to each of the items; it is possible to infer that it is a three-dimensional construct due to the high percentage of variance that it explains (Figure 1).

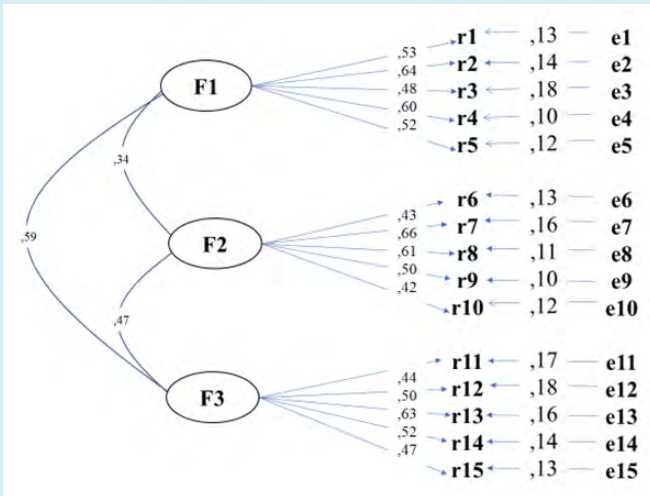

Figure 1: Structural equation modeling.

Source: Elaborated with data study. F1= Recruiter Safety Expectations; F2= Technological Security Expectations; F3= Personal Safety Expectations
The fit and residual parameters suggest the non-rejection of the null hypothesis was deduced from the fit and residual parameters $\mathrm{X}^{2}=324.35$ (21gl) $\mathrm{p}=0$ 0007; $\mathrm{GFI}=0.990$; $\mathrm{CFI}=$ $0.995 ; \operatorname{RMSEA}=0.009 ; \Pi^{2}{ }_{\text {partial }}=0.26 \mathrm{~J}$.

It is possible to note that the chi square parameter, due to the number of rotations in the confirmatory factor analysis, is significant, but the partial squared eta parameter replaces the chi square and suggests the non-rejection of the null hypothesis. The contribution of this work to the state of the question lies in the specification of a structural model explained by three factors up to $77 \%$, but the type of statistical analysis limits the results to the study sample, suggesting the contrast of the model to others study scenarios such as for-profit organizations in latitudes with levels of corruption comparable to central Mexico. Although the model is mostly explained by the three factors, there would be the possibility of including a fourth factor considering the financial protocols where fraud, identity theft and violation of privacy reduce organizations in terms of their finances [33-36].

In this way, the work of Carreon J, et al. [10] warns that cyber-espionage has had an impact on organizations dedicated to the creation of knowledge, being that in their management process they counteract their competitive advantages with spyware that reveals the innovation of your processes. In this sense, the present work has shown that the technological dimension of security is the factor that reflects organizational security, but its specificity in digital transfers and protocols will explain the remaining $23 \%$ of the total unexplained variance of the construct.

Sanchez A, et al. [31] found that innovative processes and security protocols are inherent to strategic management since, although a climate of relationships explains productivity and competitiveness through commitment, it is the climate of innovation in which determines the professional training of talents dedicated to the innovation of processes and the 
management of their security controls.

The present study, in accordance with the relationship between technology acquisition and innovation processes, found a factorial structure oriented by three factors that reflect a construct related to organizational security, but demarcated from a responsible professional training such as crime prevention within of the company $[37,38]$. This is a factor that could also explain the remaining $23 \%$ of the variance, since it is the company in charge of training its resources when they commit to a higher performance, whether or not they are encouraged by rewards and recognition.

From the point of view of the work environment, professional training free from violence oriented towards values of respect, equity and solidarity would be an effective crime prevention device in organizations dedicated to the creation of knowledge and therefore to the monitoring of their processes of quality and innovation [39]. Well, if the work commitment is related to organizational security, then professional education, training and training will be the pillars of crime prevention within organizations, proposing a comprehensive management of knowledge regarding security instrumented by any video surveillance, metal detection, or anti-spyware technology.

\section{Conclusion}

The objective of this work has been to establish the internal consistency of a model in order to be able to validate its structure and specify it to contrast it in other scenarios like the one prevailing in central Mexico. The research question was limited to the relevance of the universal explanation of the local security problem, but the accepted hypothesis suggested that the theoretical frameworks not only explain the phenomenon and rather predict it. In this sense, the study of organizational security must go through the contrast of the model that, due to its degree of percentage of explained variance, will include other factors related to computer, digital or electronic security that inhibit innovative processes in organizations dedicated to security creation of knowledge.

\section{References}

1. Aldana WIB, Sanchez RR, Garcia CL (2020) La estructura de la percepcion de la inseguridad publica. Tlatemoani 34: 52-66.

2. Bolivar E, Coronado O, Garcia C, Hernandez J (2020) Enforced disappearances and social services: Reconstruction of the Ayotzinapa, Iguala, Guerrero (central Mexico) case. Revista Eleuthera 22(1): 149-171.
3. Garcia CL (2020) Specification a model for study insecurity system. Global Journal of Management \& Business Research 20(1): 34-38.

4. Garcia C, Carreon J, Hernandez J, Bustos J (2015) Risk governance from the perception of threats and the sense of community. Mexico: UAT, pp: 71-94.

5. Carreon J (2016) Human development: Governance and social entrepreneurship. Mexico: UNAM-ENTS.

6. Bustos JM, Garcia C, Quiroz CY, Rosas FJ, Molina MR (2020) Composicion factorial confirmatoria de la percepcion de seguridad. Eureka 17(1): 85-95.

7. Bustos JMA, Garcia CL, Juarez MN (2020) Percepción de seguridad frente a la Covid 19. Investigacion Academica Sin Frontera 32(13): 1-26.

8. Bustos JM, Quintero ML, Garcia C (2017) Governance of local sustainability: Index of water mediatization for Mexico City. Tlatemoani 24: 143-159.

9. Campos G, Hernandez J, Molina HD, Garcia C (2019) Exploratiry factor structure of the social perception of security. Encuentros Multidisciplinares 62: 1-6.

10. Carreon J, Garcia C, Hernandez J (2017) Water situations, lifestyles in peripheral urban areas and struggles for water. Mexico: UNAM-CEIICH, pp: 105-128.

11. Garcia C, Carreon J, Hernandez J (2014) The professional training of human capital in the civilization of climate change. International Journal of Research in Social Sciences 10(1): 107-125.

12. Carreon J, Cruz DLPI, Santos DLM (2015) The management of social fears. Contrasts of a model of perception of insecurity in Mexico. Ehquidad 4: 31-60.

13. Garcia C, Valdes O, Sanchez R, Elizarraraz G, Mendez A, et al. (2011) Differences between Internet entrepreneurs with respect to empathy, risk perceptions and use of technological applications. Prospective 12(1): 68-75.

14. Carreon J (2013) Discourses on labor migration, return and social reintegration based on group identity in Xilitla, micro-region of Huasteca Potosina (Mexico). Mexico: UNAM-ENTS, pp: 153-174.

15. Carreon J, Garcia C, Morales M, Rosas F (2013) Labor commitment in Social Work in the health sector. Invurnus 8(2): 15-23.

16. Carreon J, Morales M, Rivera B, Garcia C, Hernandez J (2014) Migrant and merchant entrepreneurship: State of knowledge. Tlatemoani 15: 1-30.

17. Carreon J, Hernandez J, Quintero ML, Garcia C, Mejia S 


\section{Public Health Open Access}

(2016) Knowledge networks around organizational complexity: learning self-regulation, dissipation, adaptability and dynamism in the face of changes. Prospective 2(2): 57-70.

18. Carreon J, Hernandez J, Bustos JM, Garcia C (2017) Business development policies and their effects on risk perceptions in coffee growers in Xilitla, San Luis Potosi, central Mexico. Poiesis 32: 33-51.

19. Garcia C, Bustos JM, Montero M (2012) Dimensions of water sustainability. In: Carreon J, et al. (Eds.), Psychology of neoliberal globalization: analysis of social exclusion, the digital divide and sustainable development. Mexico: Diaz de Santos, pp: 117-172.

20. Garcia C, Carreon J, Mecalco J, Hernandez J, Bautista M, et al. (2013) Complex Political Systems: Implications for Sustainable Public Safety. Social Actions and Research 34: 186-216.

21. Garcia C, Bustos JM, Juarez M, Rivera BL, Limon, GA (2017) Expectations of users of the drinking water service regarding supply, quality and rates in the framework of future elections in a town in Mexico City. Compendium 4(7): 35-54.

22. Garcia C, Carreon J, Bustos J (2012) Socialization and work commitment in social workers of public and private institutions. Humanism and Social Work 11: 177-192.

23. Garcia C, Carreon J, Hernandez J, Limon GA, Morales ML (2014) The determinants of hydrological concern in Iztapalapa. In: Bustos JM, et al. (Eds.), Environmental psychology, analysis of barriers and psychosocial facilities for sustainability. Mexico, pp: 93-104.

24. Garcia C (2013) Migration insecurity in the print media. Reflections 92: 159-173.

25. Garcia C (2017) The psychological studies of agenda setting specification and discussion of a conformist versus cooperative identity model. Nomads 50: 1-18.

26. Garcia C, Carreon J, Hernandez J, Bustos JM (2014) Structure of risk perceptions around global and local water scarcity and shortage. In: Bustos JM, et al. (Eds.), Environmental psychology, analysis of barriers and psychosocial facilities for sustainability. Mexico, pp: 105118.

27. Carreon J, Hernandez J, Quintero ML (2016) Specification of a local development model. In: Del Callejo D, et al. (Eds.), Methodological guidelines for the study of development. Mexico, pp: 149-168.

28. Carreon J, Quintero ML, Hernandez J, Coronado O, Sanchez M, et al. (2019) Towards a social work of violence networks. Margin 93: 1-6.

29. Hernandez J, Carreon J, Garcia C, Aguilar JA, Lopez, LR (2017) Reliability and validity of an instrument that measures attitudes towards sustainability. In: Quintero ML, et al. (Eds.), Approaches, strategy and transdiscipline in sustainability studies. Mexico, pp: 95-110.

30. Limon GA, Rivera BL, Bustos JM, Juarez M, Garcia C (2017) Governance of climate change: specification of a model of attitudes towards climate change governments. Political Science 30: 1-31.

31. Sanchez A, Quintero ML, Sanchez R, Fierro E, Garcia C (2017) Governance of social entrepreneurship: specification of a model for the study of local innovation. Nomads 51: 1-21.

32. Sandoval FR, Carreon J, Garcia C, Quintero ML (2017) Model of the determinants of the perception of resilience based on perceived risk and stress in relation to the governance of civil protection. Invurnus 12(1): 30-35.

33. Garcia C, Carreon J, Hernandez J, Morales M (2014) Contrast of a model of work commitment in public health centers. University Act 24 (1): 48-59.

34. Garcia C, Carreon J, Hernandez J, Salinas (2016) Governance of technological innovation actors and networks. In: Quintero ML, et al. (Eds.), Innovation and technology. Challenges for its practical application in companies. Mexico, pp: 79-84.

35. Garcia C, Carreon J, Hernandez J, Bautista M, Mendez A (2012) Modeling of socio-psychological and organizational variables from the review of the state of the art. Journal of the Faculty of Social Work 28(28): 1360

36. Garcia C, Carreon, J, Hernandez J, Bustos J, Aguilar J (2015) Specification of a model of sociopolitical hyperopia. Blue Moon 42: 270-292

37. Garcia C, Carreon J, Hernandez J, Carbajal C, Quintero ML, et al. (2014) Incidence of micro-financing policies on the perception of coffee entrepreneurship and implications for Social Work. Equity 6: 11-36

38. Garcia C, Carreon J, Hernandez J, Montero M, Bustos JM (2012) Systems of political complexity. Social Work Today 65: 39-48

39. Sandoval F, Garcia H, Perez A (2015) Gender and resilience to environmental catastrophes. Ibero-American Journal of Academic Production and Educational Management $3: 1-20$.

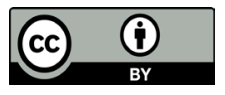

